\section{IN brief}

\section{Pfizer matchmakers in Asia}

New York-based Pfizer launched The Open Innovation Portal, a scheme aimed at luring academic institutions and early-stage biotechs based in Asia into collaborations. To those signing up to the open innovation portal (https://www. ninesights.com/community/pfizer) in return access to Pfizer's drug discovery and development expertise, Dean Mastrojohn, global media relations director at Pfizer says. "This move shows that Pfizer is aware that it needs to change its approach to innovation. Moving into this market will give Pfizer access to a huge market, as well as interesting and novel research," says Greg Scott, founder of consulting firm ChinaBio, located in Shanghai. Although the Open Innovation Portal is not a venture fund, some projects include financial support. For example, the Alliances in Therapeutic Innovation project will provide $\$ 50,000-1,000,000$ for projects in type 2 diabetes, hepatocellular carcinoma, gastric cancer, COPD (chronic obstructive pulmonary disease), and neurodegenerative and neurological diseases. Of particular interest are synthetic biology-based products and natural products amenable to synthetic chemistry or fermentation, innovative drug delivery approaches, and human genetic and proteomic studies for novel biomarkers. Others are looking east for partners, too. In March, London-based AstraZeneca signed a memorandum of understanding with the Korea Health Industry Development Institute to create an oncology research program, focusing on translational research.

Suzanne Elvidge

\section{Venter to sequence longevity}

In March, J. Craig Venter, Robert Hariri and Peter H. Diamandis launched Human Longevity, raising an initial $\$ 70$ million in private funding. The San Diego-based company announced its intention to apply genetic sequencing on a massive scale to answer questions about disease and aging. Venter vows to build the world's largest sequencing operation and has so far purchased two Illumina HISeq X Ten instruments. Human Longevity will assemble genotypic, phenotypic and microbiome information from 40,000 individuals. The database will include healthy and diseased individuals, children, adults and supercentenarians, recruited from the University of California, San Diego Moores Cancer Center. Some of the revenue will come from selling access to the raw data. Last September, Google backed Calico, an anti-aging company run by Arthur Levinson, former CEO of Genentech. Kate Bingham, of SV Life Sciences in London, says: "The real test is going to be how effective is it versus public sector efforts.... I rather doubt that [they] will be able to hold onto any of the key information." Bingham is alluding to Venter's Celera Genomics, which was unable to compete with the open access and publicly funded Human Genome Project. The nonprofit organization led by Leroy Hood, president of the Seattle-based Institute for Systems Biology, hopes to expand Pioneer 100 , the 100-person wellness project from 100 to 100,000 subjects within the next four years. Also. China's BGl launched the Million Human Genomes Project in 2011.

\title{
Indiana jumps the biosimilars gun
}

When President Barack Obama issued his fiscal year 2015 budget request last March, it contained provisions seeking to reduce the exclusivity period for biologic drugs from 12 to 7 years as a way of fostering development of biosimilar therapeutics. This specific request has a near-zero chance of moving through Congress (Obama proposed the same change for the 2014 budget). It typifies the plight of biosimilars in the US, where officials at the US Food and Drug Administration (FDA) slowly polish national guidelines for biosimilars amid feverish regulatory wrangling within state legislatures. Such maneuvers might be avoided, if the US were to join forces with the EU to regulate biosimilar drugs within a single transatlantic framework, according to the Brussels-based European Generic Medicines Association (EGA).

That recommendation is one of several set forth late last year in an EGA position paper, "EU-US Transatlantic Trade and Investment Partnership." Those recommendations were presented again this April during the Transatlantic Trade and Investment Partnership negotiations in Brussels. EGA argues that forging a single EU-US regulatory framework for biosimilar drugs would cut development costs and also avoid any "unethical duplication of clinical trials."

Before those ambitious transatlantic goals are realized, however, EU member states will need to come closer to unifying their own fragmented approach to dealing with biosimilars. Last December, for example, the French Parliament issued its 2014 Social Security Law, which includes provisions granting pharmacies partial authority to substitute biosimilars for original biological drugs.

But under the new French law, pharmacists will not be permitted to substitute biosimilars if a patient already has begun receiving therapy with the original, according to officials of the European Biopharmaceutical Enterprises (EBE), also based in Brussels. "The French law implicitly acknowledges that biosimilars cannot be regarded as interchangeable with the originator product or with each other," EBE officials note. "In this sense the French law is clearly different from the substitution policies that are applied to generic medicines where patients can often switch between different brands of the same medicine." French officials are expected to issue regulations later this year to clarify how its provisions will be implemented.

Somewhat similarly, provisions in a recently enacted state law in Indiana specify steps pharmacists are to take when substituting biosimilar products-that is, those biosimilars deemed interchangeable by FDA-for patients to use.

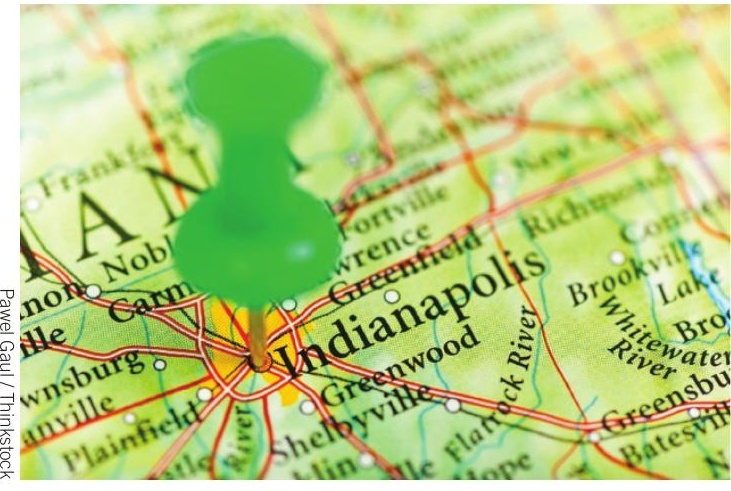

Indiana's pharmacists can now switch a biologic drug automatically for its biosimilar if it has been deemed interchangeable by the FDA.

Delaware Senate also passed legislation on April 10 to ensure patient access to interchangeable biologics. The Academy of Managed Care Pharmacy, based in Alexandria, Virginia, calls this and other state laws "premature," noting that the FDA has not yet issued guidelines for interchangeability, let alone approved any biosimilar products so far. "Until the FDA has finalized its guidelines ... a state will not know if additional steps are warranted prior to substitution of an interchangeable product or dispensing a biosimilar," says Edith Rosato, who is CEO of the organization.

Although the new Indiana biosimilars law is not as "negative or cumbersome" as some other state-level bills that are popping up, pretty much every state is going to need legislation authorizing pharmacists to dispense biosimilars within its borders, according to Bryanna Clark of the Generic Pharmaceutical Association in Washington, DC. "The question is, what's the right legislation, and what will it look like?"

Another pivotal debate is over the naming of biosimilar products. At the international level, officials of the World Health Organization are weighing whether to modify the international nonproprietary-generic-term that is used for conventional drugs when dealing with biosimilars. One possibility would be to add a fourcharacter "biological qualifier" term for each biosimilar to set it apart from the original biological therapeutic. What information the biological qualifier could convey beyond what the product's proprietary name and brand provide is at the core of the ongoing debate. FDA officials are also wrestling with questions about the naming of biosimilars, and they have promised to issue naming guidelines in advance of approving the first biosimilar products-an event whose timing remains a matter of conjecture.

Jeffrey L Fox Washington, DC 